\title{
Connect Me! Antecedents and Impact of Social Connectedness in Enterprise Social Software
}

\author{
Maurice Kügler · Sven Dittes · Stefan Smolnik • \\ Alexander Richter
}

Received: 1 July 2014/Accepted: 30 November 2014/Published online: 8 April 2015

(C) Springer Fachmedien Wiesbaden 2015

\begin{abstract}
Companies are increasingly adopting social software to support collaboration and networking. Although increasing their employees' connectedness is a major driver for organizations to deploy enterprise social software (ESS), the social connectedness concept itself is still not sufficiently defined and conceptualized. The study therefore provides a richer perspective on social connectedness's role in an ESS context. The authors thus investigate (1) social connectedness's antecedents and (2) its impact on employees' individual performance. With a survey-based investigation among 174 employees of an international business software provider headquartered in
\end{abstract}

Accepted after one revision by the editors of the special issue.

Electronic supplementary material The online version of this article (doi:10.1007/s12599-015-0379-z) contains supplementary material, which is available to authorized users.

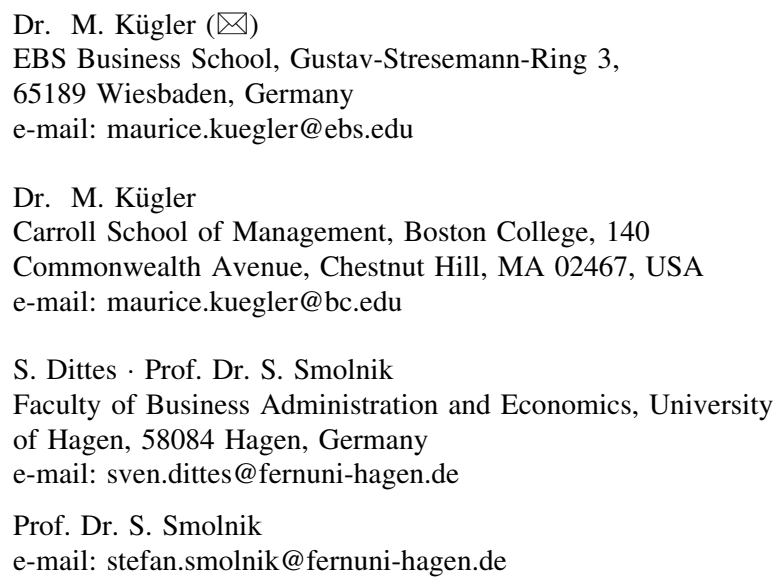
Germany, the authors show that both reputation and a critical mass significantly influence employees' social connectedness. The authors further find that reputation's effect is significantly stronger than critical mass's effect and that social connectedness influences employees' individual performance positively. The findings are discussed in the light of psychological studies and deduce implications for theory and practice.

Keywords Enterprise social software $\cdot$ Social connectedness - Impact of IS use - Individual performance · Reputation · Critical mass · Survey-based research

\section{Introduction}

The impressive growth of public social networks, such as Facebook and Twitter (Tong et al. 2008), has compelled organizations to take changing communication and collaboration patterns into account and, thus, provide their employees with intra-organizational social software (Healey 2012; Kane et al. 2014a; Kiron et al. 2013; von Krogh 2012). Today, a diverse range of organizational social software tools, such as wikis, weblogs, and social networking sites, are bundled and integrated into enterprise social software platforms, which organizations are increasingly adopting (Chan and Morgan 2011; Chui et al. 2012; Majchrzak et al. 2009). Drawing on the work of Leonardi et al. (2013, p. 2), we define enterprise social software (ESS) as: "Web-based platforms that allow workers to (1) communicate messages with specific coworkers or broadcast messages to everyone in the organization; (2) explicitly indicate or implicitly reveal particular coworkers as communication partners; (3) post, edit, and sort text and files linked to themselves or others; and 
(4) view the messages, connections, text, and files communicated, posted, edited and sorted by anyone else in the organization at any time of their choosing". ${ }^{1}$

ESS has been shown to foster collaboration and coordination between employees within organizations (e.g., Faraj et al. 2011; Kane et al. 2009; Richter and Riemer 2013). Furthermore, once they have implemented ESS, companies experience significant changes in the way their employees communicate internally (Aral et al. 2013). Although the capacity to deal with such applications is maturing slowly (Kiron et al. 2013), companies are increasingly realizing benefits and competitive advantages from using ESS (Kane et al. 2014b), such as better knowledge sharing (Chui et al. 2012), and enhanced employee innovativeness (Gray et al. 2011).

In addition to influencing information dissemination (Trier and Richter 2014) or knowledge contribution behavior (Zhang and Wang 2012), the emergent network structures are also said to transform relationships between individuals (e.g., Majchrzak et al. 2013; Riemer et al. 2015; Scheepers et al. 2014). In particular, the ease with which social software enables relationship formation is reported to cause 'a feeling of being close to other members' (e.g., Grieve et al. 2013). We refer to this phenomenon as social connectedness. While researchers have gained first empirical insights into social connectedness through public social networks (e.g., Koroleva et al. 2011; Riedl et al. 2013), empirical research on the interplay between ESS and employees' relationship formation is still scarce. This is all the more surprising given that close relationships between coworkers have been shown to not only foster knowledge exchange and collaboration (e.g., Mom et al. 2009), but to also potentially lower staff turnover rates (e.g., Riordan et al. 2005), and improve employees' work performance (e.g., Zhang and Venkatesh 2013).

Against this background, our study responds to calls for further research on relationship formation through ESS (e.g., Aral et al. 2013), as well as on ESS's potential benefits (e.g., Pawlowski et al. 2014; Richter et al. 2011). In particular, we shed light on the concept of social connectedness and investigate its antecedents, as well as its potential impact on employees' work performance. To do so, we formulate the following research questions:

1. What are the antecedents of social connectedness in the context of enterprise social software?

2. How is social connectedness related to employees' individual performance?

\footnotetext{
1 The literature also refers to these platforms as enterprise social media (e.g., Leonardi et al. 2013), enterprise social networking systems (e.g., Fulk and Yuan 2013), or enterprise social software platforms (e.g., Kügler et al. 2012).
}

This study contributes to a better understanding of social connectedness in the context of ESS. Our results further provide compelling evidence that employees' reputation and the critical mass of ESS users significantly influence employees' social connectedness. However, and surprisingly so, the effect of reputation is significantly stronger than the critical mass effect. We also find that social connectedness influences employees' individual performance positively. On the whole, these results provide a richer perspective on the role of social connectedness in the ESS context.

\section{Theorizing Social Connectedness in Enterprise Social Software}

\subsection{Theoretical Background}

The social connectedness concept is rooted in the field of psychology, ${ }^{2}$ in which studies on belongingness have revealed that people pursue the development of a personal social network in order to achieve a feeling of belongingness (Baumeister and Leary 1995; Lee and Robbins 1995). In this context, an individual's striving for connectedness is understood as a basic motivational principle that underlies human social behavior (Maslow 1968; Smith and Mackie 2007). The feeling of being socially connected can have positive effects on diverse areas (e.g., Ijsselsteijn et al. 2003), such as individuals' health and well-being (Yoon et al. 2012; Yoon and Lee 2010), and their accessible professional knowledge (Jaworski and Kohli 1993). Employees' communication and collaboration behaviors are also highly intertwined with the concept of social connectedness (e.g., Bradner 2001; Ijsselsteijn et al. 2009; Kim et al. 2007). In support of this, Rettie (2003a) finds that social connectedness is the most important driver when making a choice between different communication channels. Similarly, Lam (2013) finds that text messaging between project group members leads to stronger feelings of social connectedness within the group. The importance of social connectedness for technology-supported communications has become even more evident now that digital networks are increasingly complementing and/or replacing personal social networks (e.g., Subrahmanyam et al. 2008; Sykes et al. 2014; Zhang and Venkatesh 2013). In the

\footnotetext{
$\overline{2}$ Reviewing the current body of knowledge on social connectedness and related concepts, we found that the literature refers to the social connectedness concept in diverse ways, such as belongingness [e.g., Baumeister and Leary 1995), closeness (e.g., Suh et al. 2011; Wu et al. 2010], informal social relations (e.g., Jansen et al. 2006), and relationship building (e.g., Krasnova et al. 2010). For the sake of consistency, we use the term social connectedness throughout this study.
} 
organizational context, the wide deployment of ESS, which encompasses higher levels of social interaction and collaboration than traditional organizational IT (such as personal computers and productivity tools) (e.g., Kane and Fichman 2009), provides improved opportunities to maintain and enhance social connections through communication technology (Valkenburg and Peter 2009) and, therefore, serves as a new way to achieve a feeling of being connected.

Consequently, research on public social networks has investigated the role of social connectedness in recent years (e.g., Grieve et al. 2013; Ledbetter et al. 2011). For example, Köbler et al. (2010) find that the amount of information shared on a public social network increases users' social connectedness. In another investigation, Ellison et al. (2007) also find that the intensity of public social network use is positively related to the formation of social connectedness. Similarly, Riedl et al. (2013) find that a high use frequency of public social networks predicts users' level of social connectedness. Furthermore, research has shown that supporting social connectedness is vital for public social networks (e.g., Xu et al. 2014). These findings suggest that, in order to leverage the full potential of ESS, it is essential to understand social the influences of connectedness and its effect in respect of ESS use.

While social connectedness is often conceptualized as the number of social ties that employees have (e.g., Bandiera et al. 2008), we follow Goswami et al.'s (2010) argument that it is a subjective concept that captures the extent to which the employees themselves feel connected. Drawing on Ijsselsteijn et al. (2009), we therefore conceptualize the impact of social connectedness as the degree to which employees perceive that ESS use enables them to improve the quality, and/or increase the quantity, of relationships with their coworkers. Most of the literature on social software conceptualizes social connectedness as either an antecedent (e.g., Shin 2010) or studies it as an outcome (e.g., Riedl et al. 2013). In order to overcome this rather narrow view of social connectedness, our study contributes to a richer view of the social connectedness phenomenon. We consequently place social connectedness at the center of our study by assessing its antecedents as well as its potential impact on employees' individual performances.

\subsection{Antecedents of Social Connectedness}

The existence of a human need for social connectedness is widely acknowledged in psychology (e.g., Bowlby 1982; Ryan and Deci 2000). Acknowledging the twofold nature of the social connectedness concept, i.e. that "the connectedness construct reflects both breadth (quantity) and depth (quality) of human relationships" (Townsend and
McWhirter 2005, p. 193), we adjust this notion of social connectedness to the ESS context. We suggest that the reputation concept should represent the quality dimension since it "refers to others' perceptions of one's overall quality" (Wasko et al. 2004, p. 403). The critical mass concept, i.e. the number of people who use a certain IS (Compeau et al. 2007), represents the quantity dimension. We therefore integrate reputation and critical mass as antecedents into our research model.

\subsubsection{Reputation}

Reputation is widely considered a valuable asset for people in communities, offline as well as online (Aral et al. 2013). Moreover, the desire to build a good reputation is said to be "undoubtedly one of the most important motivations for almost any individual" (Rogers 1983, p. 215). Research has confirmed that reputation building is a strong motivator for participation (Wasko and Faraj 2005). Constant et al. (1996) show that the possibility to enhance one's reputation motivates employees to actively engage in an organizational electronic network. In IS literature, further examples of reputation's importance include studies on reputation's effects on IS use (e.g., Plouffe et al. 2001), on knowledge contribution behavior (e.g., Wasko and Faraj 2005) as well as on attitudes towards and expected benefits from social software use (e.g., Hsu and Lin 2008; Schöndienst et al. 2011). Based on Karahanna et al. (1999), we conceptualize reputation as the degree to which employees perceive that ESS use enables them to enhance their professional reputation within the organization. ${ }^{3}$

Relating this definition to employees' ESS use behavior, we surmise that employees aim at contributing high-quality content to their organizations' ESS in order to enhance their individual reputations (Phang et al. 2009). Based on their contributions, they will become more visible within the ESS and thus eventually broaden their social network within their organizations. Consequently, their personal social network will expand, leading to a stronger feeling of being connected to their coworkers. Supporting our supposition, the literature suggests that reputation encourages cooperation because individuals care about how others in a certain social group perceive them (Wasko et al. 2004). In turn, cooperative behavior promotes group members' development of identification with this group. Group identification is an important component of group formation (Ashforth and Mael 1989), which is closely connected to

\footnotetext{
3 The literature also refers to this concept as image (e.g., Moore and Benbasat 1991), recognition (e.g., Jeppesen and Frederiksen 2006), social image (e.g., Lin and Bhattacherjee 2010), online identity (e.g., Donath 1999), and self-expression/self-representation (e.g., Goffman 1959). For the sake of consistency, we use the term reputation throughout this study.
} 
our understanding of social connectedness. De Cremer and Tyler (2005) support this notion by conceptualizing an association between reputation and the feeling of group belongingness. Similarly, Lin and Bhattacherjee (2010) have established that there is a significant association between reputation and an IS's capability to allow users to foster and maintain relationships between one another. Based on the above, we hypothesize:

Hypothesis 1 (H1): reputation is positively associated with social connectedness impact.

\subsubsection{Critical Mass}

The critical mass concept refers to network externalities, i.e. to the influence that the number of people using a technology has on its value (Katz and Shapiro 1986). Once the diffusion of a new technology reaches a critical mass, its adoption rate becomes self-sustaining. The perceived critical mass's importance has been demonstrated empirically in several technological contexts, such as communication technology (Van Slyke et al. 2007), online games (Hsu and Lu 2004), mobile services (Cho 2011), and instant messaging ( $\mathrm{Li}$ et al. 2005; Lin and Bhattacherjee 2008; Wang et al. 2004). While it is difficult to measure an actual critical mass threshold for collaborative technologies (Markus and Connolly 1990), users may - through interactions with others - have a perception of whether a certain technology has achieved a critical mass of users (Lou et al. 2000). Drawing on Compeau et al. (2007), we conceptualize critical mass as the degree to which employees perceive that a large number of their coworkers use an ESS. ${ }^{4}$

Critical mass is known to be of particular importance for social software, since it represents the actual users who make the software valuable by contributing user-created content (e.g., Krasnova et al. 2012; Sledgianowski and Kulviwat 2009). Studies have already confirmed critical mass's crucial role in technological diffusion in the context of public social networks (e.g., Lin and Lu 2011) and in an ESS context (e.g., Wattal et al. 2010). Research has further shown that a large number of users could exercise normative pressure on those employees not using the ESS, or it could serve as a mechanism to motivate users to join an ESS in order to achieve a sense of belonging (Hester 2011; Venkatesh and Morris 2000). Additionally, research on social connectedness has suggested that the size of a social network is one of its main determinants in the realm of public social networks (Riedl et al. 2013). Furthermore, Köbler et al. (2010) confirm the significant influence that

\footnotetext{
4 The literature also refers to this concept as visibility (e.g., Karahanna et al. 1999), or others' use (e.g., Compeau et al. 2007). For the sake of consistency, we use the term critical mass throughout this study.
}

network size has on social connectedness in a public social network context. Based on her research on instant messaging and following the critical mass idea, Rettie (2003b) states that the mere feeling of being able to contact a large number of people, even if there is no actual contact through social software, already has a remarkable influence on people's feeling of being connected. Similarly, as the perceived number of ESS users increases, employees will perceive the technology as an enabler to reach out to more people through its use (Lu et al. 2010). Hence, a higher number of connections should yield access to more interpersonal resources (Gao et al. 2013). Following these arguments, we hypothesize:

Hypothesis 2 (H2): critical mass is positively associated with social connectedness impact.

\subsection{The Outcome of Social Connectedness: Individual Performance Impact}

Based on Goodhue and Thompson (1995), we conceptualize individual performance impact as the extent to which employees perceive their ESS use to improve their ability to accomplish their work tasks (i.e. their work efficiency). ${ }^{5}$ Besides fostering trust and cooperation between employees (Adler and Kwon 2002), social connectedness enables employees to access a more diverse knowledge base throughout their organizations (Jaworski and Kohli 1993). Moreover, having strong relationships with their coworkers enables employees to share experiences with regard to how to implement certain improvements (e.g., in work processes) (Dyer and Nobeoka 2000). In general, organizational science research (e.g., Burt 1992) and IS research (e.g., Alavi and Leidner 2001) both argue that better access to and referrals of knowledge improve individual performance. Furthermore, several studies have shown that better knowledge access improves employees' performances (e.g., Cross and Cummings 2004; Hansen 1999; Teigland and Wasko 2003; Wu 2013; Zhang and Venkatesh 2013). In the current knowledge-intensive work environment, individuals' performances depend strongly on their access to the right knowledge sources within their organizations (e.g., Gray and Meister 2004). We therefore expect social connectedness to improve employees' individual performances and, thus, hypothesize:

Hypothesis $3(\mathrm{H} 3)$ : social connectedness impact is positively associated with individual performance impact.

Figure 1 depicts our proposed research model.

\footnotetext{
5 Please note that this concept measures the impact that ESS use has on an individual's performance [see Goodhue and Thompson (1995), Iivari (2005), and Sundaram et al. (2007) for similar conceptualizations of performance outcome variables].
} 
Fig. 1 Research model

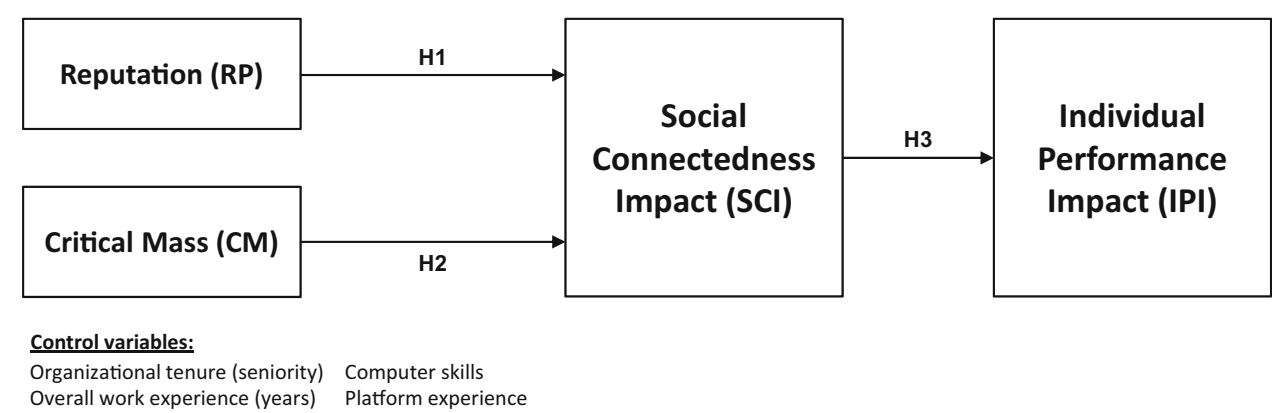

\section{Research Process and Methods}

\subsection{Research Site}

To assess our theoretical model empirically, we follow a quantitative, survey-based research approach. Since the type of ESS available, and the degree to which an organization's culture encourages employee collaboration and knowledge sharing, may potentially constrain or encourage individuals' ESS use behaviors (e.g., Gray and Meister 2004), we controlled for both possible sources of variation by testing our research model within a single organization. We collected survey-based data at an international business software provider (hereafter referred to as "SoftCom") with more than 50,000 employees dispersed throughout the world and headquartered in Germany. A member of SoftCom's ESS project team (who is in charge of maintaining and promoting the company's ESS between its employees) agreed to distribute our survey to a subset of SoftCom's employees. In exchange, we offered SoftCom a report describing our study's practical findings and implications. At the time of the data collection (May/June 2013), SoftCom had been using several types of social software (like wikis and weblogs) for about 8 years. However, the platform under study - which provides SoftCom's employees with a rich set of features, including social networking, weblogs, wikis, micro-blogging, instant messaging, tagging, e-mail integration, team rooms, and online surveys had only been in place for about 8 months. It had more than 30,000 monthly unique users when the study commenced.

\subsection{Survey Instrument}

We followed Straub's (1989) guidelines during the instrument development process. Following several researchers' recommendations (e.g., Kankanhalli et al. 2005; Stone 1978), we adapted tested and proven measures from the literature. Thereafter, we modified the identified items for use in the ESS context. We created initial item pools for each of the constructs, subsequently reducing the number of items for the measurement instrument by conducting two research workshops, with three researchers involved in each (MacKenzie et al. 2011), during which the participants evaluated each candidate item's relevance for the potential target construct (Cronbach 1971). In a next step, we conducted two rounds of card sorting and item ranking exercises (Moore and Benbasat 1991) with a group of five IS researchers per round. ${ }^{6}$ Lastly, we recruited ten social software users to test the actual online questionnaire. After the participants completed the questionnaire, we conducted semi-structured interviews on the format of the scales, the questionnaire's length, potential question ambiguity, as well as on any technical or non-technical issues. The survey instrument was constantly adjusted and refined to reflect the feedback received from the outlined process.

The reputation (RP) items were adapted from the items used by Hsu and Lin (2008), Kankanhalli et al. (2005), and Schöndienst et al. (2011). Critical mass (CM) was measured using scales adapted from Hsu and $\mathrm{Lu}$ (2004), Thompson et al. (1991), and Van Slyke et al. (2007). Items measuring the social connectedness impact (SCI) were adapted from the measures used by Bock et al. (2005) and Krasnova et al. (2010). The individual performance impact (IPI) construct was adapted from Goodhue and Thompson (1995), Iivari (2005), Urbach et al. (2010), and Venkatesh et al. (2003). Except for the demographic data, all the items were measured using seven-point Likert-type scales anchored on 1 (strongly disagree) and 7 (strongly agree). All the constructs were operationalized as reflective constructs. The final items used in this study are shown in Online Appendix A.

We further included the following individual characteristics as control variables: organizational tenure (seniority), overall work experience (years), computer skills, and platform experience (months). Organizational tenure and age have both been shown to be associated with employees' job performance (e.g., Brenner et al. 1988; Gould and Werbel 1983; Tesluk and Jacobs 1998). Since the two characteristics are typically correlated (Sykes et al. 2014), we only controlled for organizational tenure during our

\footnotetext{
$\overline{6}$ The specific procedures followed as well as the results of these exercises, are available from the authors on request.
} 
data analysis. Research has shown that individuals' confidence in their computer skills might have a positive influence on their performance (e.g., Compeau and Higgins 1995a, b) and, therefore, we included computer skills as a control variable. Since prior research (e.g., Jasperson et al. 2005) further suggests that individuals' IS use history influences their use behaviors, we decided to control for users' platform experience.

\subsection{Pre-Study}

As some of the constructs included in our research model had not yet been applied to the ESS context, we carried out a preliminary study to validate the proposed measures in the ESS context before collecting data at our main study's research site. This measurement validation study included 86 employees of an international company from the communications and high-tech industry, headquartered in Germany. ${ }^{7}$ After ensuring, by means of the pre-study, that the psychometric properties of the constructs included in our research model were sound, we tested the proposed hypotheses in our main empirical study.

\subsection{Data Collection}

In May 2013, our contact person at SoftCom sent an e-mail containing a hyperlink to our study's online survey to 3500 employees. He encouraged the recipients to participate and added that the survey results would benefit SoftCom. In the e-mail, as well as on the landing page of the online survey, we informed the employees that all the gathered data would be handled anonymously and strictly confidentially. After 2 weeks, an e-mail reminder was sent to the potential study participants. We closed the online survey after 4 weeks.

\subsection{Sample Characteristics}

A total of 174 employees fully completed the online survey. Since all the online survey questions were mandatory, we did not have to deal with missing or incomplete responses. However, we had to exclude 28 data sets during the data cleaning, since the survey answers were too similar (e.g., all the Likert-scaled items were answered with the same value), resulting in a final number of 146 usable data sets. At the time of the investigation, the survey respondents had been working for SoftCom for an average of 7.1 years, while their overall professional work experience averaged 17.2 years. On average, they had 5.9 months' experience working with SoftCom's ESS (see

\footnotetext{
$\overline{7 \text { The results }}$ of the pre-study are available from the authors on request.
}

Table 1 Descriptive statistics and psychometric properties

\begin{tabular}{llllllllll}
\hline & Mean & SD & CR & AVE & CA & CM & IPI & RP & SCI \\
\hline CM & 3.38 & 1.88 & 0.98 & 0.94 & 0.97 & $\mathbf{0 . 9 4}$ & & & \\
IPI & 3.39 & 1.94 & 0.99 & 0.98 & 0.99 & 0.34 & $\mathbf{0 . 9 8}$ & & \\
RP & 3.34 & 1.72 & 0.99 & 0.97 & 0.99 & 0.28 & 0.31 & $\mathbf{0 . 9 7}$ & \\
SCI & 3.70 & 1.89 & 0.98 & 0.95 & 0.97 & 0.24 & 0.45 & 0.40 & $\mathbf{0 . 9 5}$
\end{tabular}

The diagonal elements (bold) represent the AVE; the off-diagonal elements are the squared correlations of the factors. To ensure discriminant validity, the diagonal elements should be larger than the off-diagonal elements (Fornell and Larcker 1981)

All the items underlying the above constructs were measured using seven-point Likert-type scales (1, strongly disagree; 7, strongly agree) $S D$ standard deviation, $C R$ composite reliability, $A V E$ average variance extracted, $C A$ cronbach's alpha, $C M$ critical mass, IPI performance impact, $R P$ Reputation, $S C I$ social connectedness impact

Online Appendix B for more insights into the respondents' demographic characteristics).

\section{Data Analysis}

We utilized the partial least squares (PLS) approach, a component-based structural equation modeling technique, to analyze the survey-based data. PLS is particularly suitable for theory development purposes with the objective of maximizing the explained variance in the outcome variables (Chin 1998; Gefen and Straub 2005). We used SmartPLS 2.0 M3 (Ringle et al. 2005) to validate the proposed research model. Our data analysis was guided by the recommendations of Chin (1998), Gefen et al. (2011), and Hair et al. (2012a, b).

\subsection{Measurement Model}

We first assessed whether each of the measurement items relates better to its respective construct than to any other construct (Gerbing and Anderson 1988). We therefore carried out an exploratory factor analysis (EFA) using SPSS 21.0 (IBM Corporation 2012). The results confirmed that all the measurement items load highly on only one factor and that all the loadings are well above the suggested threshold of 0.600 (Gefen and Straub 2005). ${ }^{8}$ We then assessed the measurement model's descriptive statistics and its psychometric properties (Table 1). The Cronbach's alpha (CA) (Cronbach 1951) and composite reliability (CR) (Chin 1998) values of all the measures are well above the recommended values of 0.50 and 0.70 , respectively (Nunnally and Bernstein 1994), indicating high internal

\footnotetext{
$\overline{8}$ The results of the exploratory factor analysis are available from the authors on request.
} 
Table 2 Results of the main analysis

\begin{tabular}{lllrl}
\hline Hypothesis & & Path coefficient & $t$ value & Hypothesis outcome \\
\hline H1 & RP $\rightarrow$ SCI & 0.515 & $12.262^{* * *}$ & Supported \\
H2 & CM $\rightarrow$ SCI & 0.197 & $4.098^{* * *}$ & Supported \\
H3 & SCI $\rightarrow$ IPI & 0.652 & $20.285^{* * *}$ & Supported \\
\hline
\end{tabular}

A two-tailed test was performed

$C M$ critical mass, $I P I$ individual performance impact, $R P$ reputation, $S C I$ social connectedness impact

*** $p<0.001$

consistency of all the constructs. We further evaluated the model's convergent validity by assessing (1) the average variances extracted (AVE) (Fornell and Larcker 1981) as well as (2) all the items' indicator loadings. The AVE of all the constructs is higher than the threshold of 0.50 (Fornell and Larcker 1981). A bootstrapping procedure with 1000 resamples showed that all the indicator loadings are significant at the 0.001 level.

The measurement model's discriminant validity was assessed by (1) examining the items' cross-loadings and (2) by means of the Fornell-Larcker criterion (Fornell and Larcker 1981). The items' loadings and cross-loadings (Online Appendix C) show that all the items correlate best with their intended constructs and that all the cross-loading differences are higher than the suggested threshold of 0.1 (Gefen and Straub 2005). Furthermore, all the constructs load highest with their assigned items, as recommended by Chin (1998). The AVE values of each construct exceed all the respective squared interconstruct correlations (Table 1), thus meeting the Fornell-Larcker criterion (Fornell and Larcker 1981).

\subsection{Structural Model}

With a robust measurement model in place, we tested the structural model further by means of a bootstrap analysis (1000 subsamples; sample size equal to 146). Evaluating the structural paths between our research model's constructs, we considered the hypothesized effects supported if the corresponding path coefficients had the predicted sign, had values of 0.10 or higher, and were significant at the $p<0.05$ level (Meehl 1990). The effect size of each of the model's main effects was assessed by means of Cohen's (1988) $f^{2}$, which allows for determining an independent latent variable's substantial impact on a dependent latent variable. The $f^{2}$ values exceeding the thresholds of 0.02 , 0.150 , and 0.350 were respectively labeled small, medium, and large effects (Chin et al. 2003; Cohen 1988; Gefen et al. 2011). The results show that our data fully supports hypothesis $\mathrm{H} 1 \quad\left(\beta_{\mathrm{RP} \rightarrow \mathrm{SCI}}=0.515, p<0.001, f^{2}=0.34\right.$, effect size: medium). Similarly, the data also confirms hypotheses $\mathrm{H} 2\left(\beta_{\mathrm{CM} \rightarrow \mathrm{SCI}}=0.197, p<0.001, f^{2}=0.04\right.$, effect size: small $)$ and $\mathrm{H} 3\left(\beta_{\mathrm{SCI} \rightarrow \mathrm{IPI}}=0.652, p<0.001\right.$, $f^{2}=0.73$, effect size: large). The squared multiple correlations $\left(R^{2}\right)$ are respectively 0.448 and 0.470 in respect of social connectedness impact (SCI) and individual performance impact (IPI), meaning that the identified antecedents explain $44.8 \%$ of the SCI variance and $47.0 \%$ of the IPI variance. The results of the structural model's assessment are summarized in Table 2. In total, the results fully support all three hypotheses (Fig. 2).

We further assessed the control variables' effects on SCI and IPI, finding that platform experience $(\beta=0.101$, $p<0.010)$ and organizational tenure $(\beta=0.049$, $p<0.100$ ) have positive significant effects on IPI and that the overall work experience has a negative significant effect on SCI $(\beta=-0.085, p<0.010)$, while computer skills has no significant effect on either of the dependent variables (see Online Appendix D for further details). Since (1) the corresponding path coefficients have rather low values and (2) the explained variance of all of the control variables only amounts to $8.5 \%$ (SCI) and $8.1 \%$ (IPI) of the dependent variables' variance, the control variables do not need further attention in the following data analysis and interpretation.

\subsection{Post-Hoc Analyses}

\subsubsection{The Differential Effects of Reputation and Critical Mass}

The results of our main data analysis suggest that reputation's influence on $\mathrm{SCI}\left(\beta_{\mathrm{RP} \rightarrow \mathrm{SCI}}\right)$ is significantly stronger than the effect of critical mass on SCI $\left(\beta_{\mathrm{CM} \rightarrow \mathrm{SCI}}\right)$. In order to test for this assumed effect, we conducted a post hoc analysis to test the differential effects between the two paths $\beta_{\mathrm{RP} \rightarrow \mathrm{SCI}}$ and $\beta_{\mathrm{CM} \rightarrow \mathrm{SCI}}$. We compared the two path coefficients by means of the pooled standard error method for path comparison that Chin (2004) suggests (see Online Appendix E for the relevant formula). To further confirm the results, we also applied the Satterthwaite method (Satterthwaite 1946). The results are consistent with Chin's (2004) assumption that, given the sufficient sample size, which our data supports, the results obtained from the two 
Fig. 2 Results of the structural model assessment including a differential effects analysis

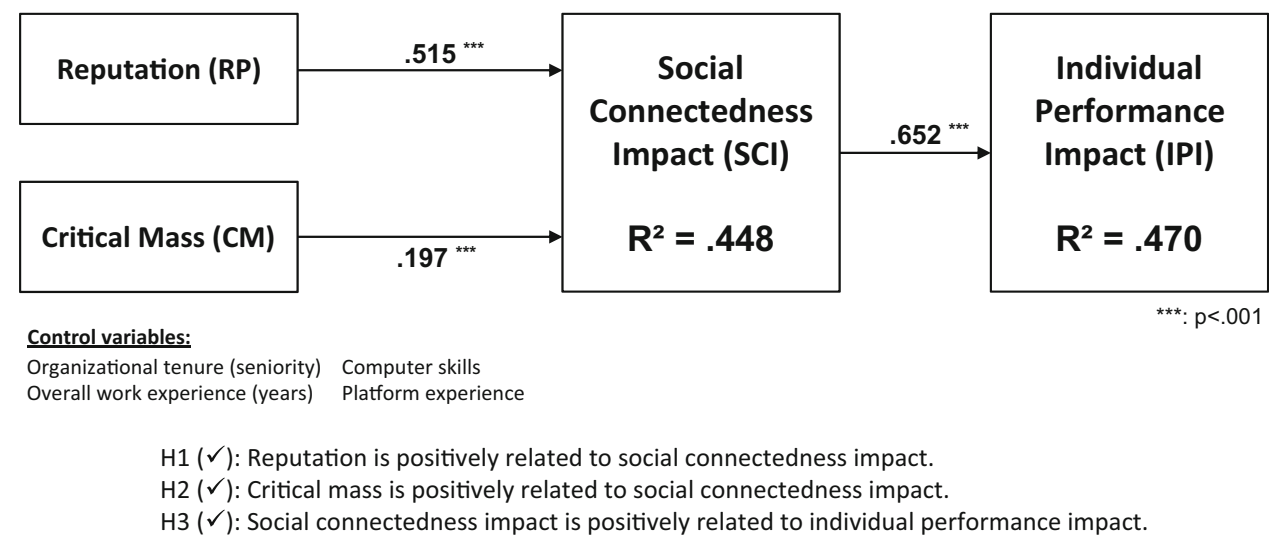

Table 3 Results of path comparison tests

\begin{tabular}{llll}
\hline Path coefficient & Pooled standard error method & Satterthwaite method & Conclusion \\
\hline$\beta_{\mathrm{RP} \rightarrow \mathrm{SCI}}$ vs. $\beta_{\mathrm{CM} \rightarrow \mathrm{SCI}}=0.515^{* * *}$ vs. $0.197^{* * *}$ & $t=4.988^{* * *}$ & $t=4.971 * * *$ & $\beta_{\mathrm{RP} \rightarrow \mathrm{SCI}}>\beta_{\mathrm{CM} \rightarrow \mathrm{SCI}}$
\end{tabular}

A two-tailed test was performed

$C M$ critical mass, $R P$ reputation, $S C I$ social connectedness impact

$* * * p<0.001$

tests should be similar. Table 3 reports the results of both path comparison tests.

The results show that reputation's influence on SCI $\left(\beta_{\mathrm{RP} \rightarrow \mathrm{SCI}}\right)$ is significantly stronger $(t=4.988 ; t=4.971)$ than critical mass's effect on SCI $\left(\beta_{\mathrm{CM} \rightarrow \mathrm{SCI}}\right)$.

\subsubsection{Mediation Analyses}

To assess our model's full nomological validity (Lowry and Gaskin 2014), we subsequently conducted two mediation analyses, one to test whether SCI mediates the relationship between reputation and IPI, and one to test whether SCI mediates the relationship between critical mass and IPI. A mediator is a construct in a causal chain between an antecedent construct and a successor construct (Baron and Kenny 1986). We performed the mediation test that Baron and Kenny (1986) propose, as well as the Sobel test (Sobel 1982) to establish the mediation effects (Helm et al. 2010).

According to Baron and Kenny (1986), a mediation effect is present if the following requirements are fulfilled: (1) the independent variable must predict the mediating variable; (2) the mediating variable must be a predictor of the dependent variable; (3) if the mediator is absent from the model, the independent variable must predict the dependent variable; and (4) when the mediator is integrated into the model, the independent variable's effect on the dependent variable must either decrease (partial mediation) or become insignificant (full mediation). Transferred to our model, reputation and critical mass (independent variables) influence SCI (mediating variable) significantly, which in turn has a significant relationship with IPI (Table 2), thus fulfilling requirements (1) and (2). Further, both independent variables predict the dependent variable in the absence of the mediator variable $\left(\beta_{\mathrm{RP} \rightarrow \mathrm{IPI}}=0.337, p<0.001\right.$; $\beta_{\mathrm{CM} \rightarrow \text { IPI }}=0.400, p<0.001$; see Online Appendix F). When SCI is integrated back into the model, reputation's significant effect on an employee's IPI diminishes $\left(\beta_{\mathrm{RP} \rightarrow \mathrm{IPI}}=\right.$ 0.098, $p>0.05$; see Online Appendix F). This means that SCI fully mediates the influence of reputation on IPI. Critical mass's influence on IPI decreases, but remains significant $\left(\beta_{\mathrm{CM} \rightarrow \text { IPI }}=0.309, p<0.001\right.$; see Online Appendix F), meaning that SCI only partly mediates the influence of critical mass on IPI. We subsequently performed the Sobel test (Sobel 1982), leading to the conclusion that SCI does mediate the influence of reputation on IPI (6.105, $p<0.001)$ and the relationship between critical mass and IPI $(3.029, p<0.010)$.

\section{Discussion and Implications}

\subsection{Discussion of Results}

Summarizing our findings, we empirically validate that reputation is positively associated with social connectedness impact (H1). Similarly, a positive relationship could be shown between critical mass and social connectedness impact (H2). Our study further reveals that social connectedness impact is positively associated with individual 
performance impact (H3). Additionally, and counter-intuitively, we demonstrate that reputation has a significantly stronger effect on social connectedness impact than critical mass has. Our initial expectation was that an employee's perception of critical mass, i.e. the number of ESS users, would have a stronger influence on social connectedness impact. Research on public social networks has provided a possible reason why reputation has a significantly stronger impact on social connectedness. It shows that most of an individual's relationships on ESS platforms are derived from the offline world, i.e. users mainly connect with existing friends and family members (Ellison et al. 2007; Ross et al. 2009). Applying this observation to our notion of social connectedness and its antecedents, consisting of a quality dimension (reputation) and a quantity dimension (critical mass), the quality dimension, i.e. improving the quality of existing relationships, seems to prevail in an enterprise context. The potential that employees have to improve their professional reputation within their organizations (quality dimension) plays a significantly stronger role in social connectedness formation than the critical mass of users who are engaged in the platform (quantity dimension) does. Baumeister and Leary (1995) refer to this as a "desire for interpersonal attachments" or a "need to belong". In their study, they identify a "need to form and maintain strong, stable interpersonal relationships [...] for frequent, nonaversive interactions within an ongoing relational bond" (Baumeister and Leary 1995, p. 497).

\subsection{Theoretical Implications}

Our study makes several contributions to the research literature. First, while there are a few conceptualizations of social connectedness on public social networks (e.g., Grieve et al. 2013), our study is among the first to conceptualize and subsequently apply the social connectedness concept in an ESS setting. The proposed social connectedness construct can be readily used in future studies on organizational IS and its interplay with social connectedness. Moreover, we contribute to a richer perspective on the social connectedness concept in an enterprise setting, thus, rectifying the rather single-sided investigations into social connectedness as either an antecedent (e.g., Shin 2010), or an outcome (e.g., Riedl et al. 2013). Our study integrates social connectedness's antecedents, focal construct, and impact on employees' performance, and thereby enables future researchers to build on the proposed model and extend it to meet their research settings and needs. We further establish social connectedness as a full mediator of the relationship between reputation and individual performance, and as a partial mediator impact of the relationship between critical mass and individual performance. Previous studies have revealed reputation's (e.g., Compeau et al.
2007; Schöndienst et al. 2011) and critical mass's (e.g., Van Slyke et al. 2007) direct positive influences on performance impact, meaning that higher degrees of reputation and of critical mass predict a higher performance impact. Our results extend this understanding and suggest that the association between reputation and individual performance impact will only hold true in the presence of social connectedness. Similarly, the influence of critical mass on individual performance impact is partially dependent on social connectedness.

Second, we transfer findings from psychology research to the IS discipline in order to identify two concepts preceding social connectedness in the ESS context: reputation and critical mass. We moreover determine reputation's significantly stronger influence on social connectedness, suggesting that researchers should pay particular attention to reputation's role in future social connectedness studies. Our findings regarding $\mathrm{H} 2$ (the positive association between critical mass and social connectedness) are consistent with the network externality model (Katz and Shapiro 1986) and the critical mass theory of interactive media (Markus 1987). However, this finding contradicts recent findings by Riedl et al. (2013), who do not find a significant relationship between network size and social connectedness in their investigation of Twitter users. A potential reason for this might be the overall smaller number of potential users in an enterprise setting (in the case of SoftCom's $50,000+$ potential users versus Twitter's hundreds of millions of users), which explains the higher importance of reaching a certain threshold of users for ESS.

Third, by combining our study's findings regarding social connectedness's antecedents with Venkatesh and Morris's (2000) argument that others' use "can be expected to be critical in the short-term when one has little or no prior experience with a specific technology (i.e. in the early stages of acceptance and usage)" (p. 122), we suggest that critical mass might be of greater importance during the early stages of users' experience with ESS (short-term), while reputation gains importance when users become more acquainted with ESS (long-term). This proposition is in line with Karahanna et al.'s (1999) findings. These authors' study of potential adopters of an IS identifies a significant association between the respondents' perception of critical mass and their attitude to adopting the IS, but a non-significant relationship between their perception of reputation and their attitude to adopting the IS. However, when assessing the actual IS users, they find that the association between critical mass and their attitude to continuing using the IS is non-significant, but that their perception of reputation then significantly predicts their attitude to continuing using the IS (Karahanna et al. 1999). Future research could further investigate this phenomenon, for example, by assessing the potential moderating effect of 
prior IS use on the relationship between reputation and social connectedness.

Fourth, based on research assessing the positive outcomes of social connectedness in offline contexts (e.g., Lee et al. 2001) and in the context of public social networks (e.g., Koroleva et al. 2011), our study contributes to the social connectedness research stream by investigating social connectedness' outcome in an ESS setting. By confirming social connectedness's positive effect on employees' individual performance in a workplace setting, our study expands the previous findings to the ESS context. Our findings contradict the findings of Roca and Gagné (2008), who, in their study on e-learning in an organizational context, find that the relationship between employees' social connectedness and their performance outcomes is insignificant. A potential explanation for this is the technicality of the platform under study. On the one hand, the e-learning platform that Roca and Gagné (2008) investigate targets "improving professional and analytical skills" (p. 1593), which can be considered rather long-term benefits. On the other hand, ESS, with its potential communication, collaboration, and coordination benefits, offers employees short- and long-term benefits ( $\mathrm{Wu}$ 2013). Employees might therefore be better able to perceive (and subsequently report) ESS's performance impacts than those obtained from an e-learning platform.

Fifth, our findings can be integrated into motivation theory as a theoretical perspective. Whereas intrinsic motivation refers to the pleasure and inherent satisfaction derived from a specific activity (Vallerand 1997), extrinsic motivation emphasizes performing a behavior to achieve a specific goal (e.g., rewards or monetary incentives) (Deci and Ryan 1987; Venkatesh 1999). In addition to intrinsic and extrinsic motivations, Ryan and Deci (2000) introduce a continuum of motivations - from intrinsic towards more and more extrinsic motivations: external motivation, introjected motivation, identified motivation, and integrated motivation. External is the closest to extrinsic motivation while integrated is closest to intrinsic motivation. Relating motivation theory to our results, we suggest regarding reputation as an identified motivation, meaning that the relevant behavior is considered personally important (Ryan and Deci 2000). Critical mass can be categorized as introjected motivation, which typically triggers behaviors that people feel they should perform in order to feel accepted and to be of value ( $\mathrm{Gu}$ and Jarvenpaa 2011). Hence, based on Ryan and Deci's (2000) continuum of motivations, we consider reputation to be a rather intrinsic motivator, while critical mass is a more extrinsic motivator.

\subsection{Managerial Implications}

Our research also has implications for organizations using ESS, ESS users, and ESS providers:
Prior research has shown that close relationships between coworkers might lead to organizational benefits, such as improved knowledge exchanges and collaborations between coworkers (e.g., Mom et al. 2009), and a decrease in staff turnover rates (e.g., Riordan et al. 2005). Our study extends these findings by showing that employees not only feel more connected to their colleagues when using ESS, but also complete their work tasks more quickly. Given the general skepticism regarding ESS use and its potential benefits for employees and organizations (e.g., McAfee 2009), our study may help IT managers justify ESS investments and articulate convincing value propositions for launching organizational social software initiatives. Our analyses' findings may also help disseminate ESS's benefits and use cases to potential users to get them 'on board' during their organizational rollouts. Since employees do not necessarily use the provided ESS as expected, which often leads to platforms that "starve for attention" (Healey 2011 , p. 1), this approach might be of particular interest to organizations adopting ESS.

Furthermore, our study provides organizations with valuable insights into the formation of social connectedness between their employees. In order to make employees feel connected through their use of an ESS, both reputation and critical mass should be taken into consideration, while acknowledging reputation's significantly stronger influence on social connectedness.

Our findings demonstrate that ESS adopters' visible activities (i.e. critical mass) influence employees' social connectedness perceptions; consequently, managers wishing to increase their employees' social connectedness should try to cultivate the impression that there is a critical mass of ESS users. Managers can convey the impression of a critical mass by initially encouraging ESS use in teams likely to adopt it quickly, which should lead to cascading perceptions of critical mass. Since diffusion networks can be referred to as 'networks of networks' with multiple subnetworks within the overall diffusion network, it seems reasonable to expect the degree of adoption within individuals' visible and relevant sub-network to strongly influence their perception of critical mass (Van Slyke et al. 2007). Venkatesh and Morris's (2000) argument that users will, particularly in the early stages of IS use, "tend to comply with others' views and intend/use the target system to attain a favorable reaction from important referents" ( $p$. 122), further supports this notion.

This research's findings further indicate that employees' perceptions of whether ESS use will enhance their professional reputation predict their social connectedness. Hence, a reputation management approach seems advisable. Reputation mechanisms aimed at characterizing user engagement quantitatively, such as the number of posts and followers, have been in place in enterprise community 
platforms for a while [e.g., a real-time list of the top users of an online discussion board at Hewlett Packard ( $\mathrm{Gu}$ and Jarvenpaa 2003)]. Recently, more sophisticated reputation mechanisms, referred to as gamification, have gained popularity (Hamari et al. 2014). Gamification refers to the integration of game-inspired elements into non-gaming environments to incentivize certain user behaviors (Huotari and Hamari 2012). Although gamification has proven beneficial in some ESS contexts (e.g., Farzan et al. 2009), its introduction could have downsides (e.g., Thom et al. 2012). Since gamification elements mainly target users' extrinsic motivation, the crowding-out effect (Frey and Jegen 2001), which involves extrinsic motivation undermining intrinsic motivation, explains a potential threat to the gamification approach (Gu and Jarvenpaa 2003). Our results support the notion that reputation, i.e. a qualitative account, which is normally not considered in gamification elements, has a stronger impact on social connectedness (and, eventually, on individual performance) than quantifiable numbers typically displayed in gamification elements (such as the number of posts and followers). Hence, gamification's advantages and disadvantages should be considered carefully prior to the organizational rollout of ESS.

Based on the above, we advise organizations to leverage the importance of personal reputation management through ESS use in the following ways: (1) employees who contribute high-quality content are likely to enjoy an enhanced reputation (Phang et al. 2009). We therefore first and foremost recommend IT managers, who are in charge of organizational social software initiatives to focus on increasing employees' awareness of high-quality content's importance (by means of, e.g., launching awareness campaigns, or promoting success stories). (2) Participation in ESS should not be anonymous to allow for high-quality content and its authors to be acknowledged (Iivari 2014). We therefore recommend that organizations should utilize user profiles to make ESS users identifiable and recognizable throughout the organization (Utz 2010). (3) After thorough considerations, organizations should decide which of the introduced reputation mechanisms they deem most suitable for introduction into their organizational setting (e.g., user statistics only available to administrators through the ESS backend versus a gamification approach, including a leadership board and achievement badges).

Our analysis has the following implications for ESS users: first, by confirming social connectedness's positive association with individual performance, users can justify their ESS use to their management. Second, our results provide insights into how users can leverage ESS to become better connected within their organization. More specifically, to become better connected to their coworkers, ESS users should take aspects of reputation and of critical mass into consideration. Third, we identify reputation as the significantly stronger predictor of social connectedness. In line with Phang et al. (2009), we therefore advise users to actively use ESS and contribute high-quality knowledge in order to improve their professional reputation in their organizations and, as a consequence, to extend their social network.

Our findings on social connectedness also provide suggestions for ESS providers: first and foremost, ESS should provide their users with effortless functionality to build and maintain relationships with their coworkers (Lampe et al. 2007). Further, the technical platform should support social connectedness's relevant determinants, reputation, and critical mass. In addition, the overarching design guideline should be to provide customers (i.e. organizations introducing ESS) with various options to measure, control, and improve reputation. Users will certainly be interested in questions, such as "How good is my reputation in various communities?" The ESS should therefore offer a set of standard reports on users' reputations. ESS should also provide easy-to-use functionality to enable users to create content and, subsequently, edit, delete, share, rate, and comment on it. Changes in the user interface should be taken into consideration here as well. In their research on interface changes in a group collaboration environment, Jung et al. (2010) show that slight manipulations of the human-computer interface can significantly contribute to a collaborative IS's success. Although reputation's effect on social connectedness is significantly stronger, critical mass should also be taken into account in ESS design choices. ESS providers should ensure that ESS use is an interactive experience, allowing its users to easily notice others on the platform and, hence, gain a better perception of the critical mass of users.

\section{Conclusion, Limitations, and Future Research}

This study introduces the social connectedness concept to the enterprise social software context by shedding light on the construct itself, its antecedents, and its impact on employees' work performance. In this context, we conceptualize employees' social connectedness as the degree to which ESS helps employees strengthen their relationships with their coworkers. The survey-based data of our research was collected among 174 employees of an international business software provider headquartered in Germany. Reputation and critical mass were shown to be two main causes of employees' social connectedness, with reputation having a significantly stronger influence than critical mass. We further confirm social connectedness's positive association with individual work performance and thereby establish social connectedness as a crucial 
mediating variable in the causal chain explaining social software's impact on employees' work performance. Considering this concept will benefit IS researchers in understanding ESS phenomena better and practitioners in launching and managing social software initiatives.

Despite its various contributions to theory and practice, our study has a number of limitations that might stimulate future research. Owing to our study's cross-sectional design, it only captures information at a certain point in time and cannot determine the actual causality of the included concepts. We therefore encourage researchers to conduct a longitudinal research study to replicate or extend our findings with a longitudinal data set.

Our study's results are further limited by the response rate, which was rather low in spite of the a priori measures we took in order to prevent a low response rate (e.g., ensuring respondents' anonymity, stressing the questionnaire's importance, and sending a follow-up e-mail). However, the response rate was not much lower than that of similar studies (e.g., Wilden and Gudergan 2014), especially if one considers that: (1) the overall survey was quite extensive in length; (2) the respondents were all professionals of SoftCom, partly with high seniority; (3) the respondents were not offered an incentive for taking part in the survey; and (4) incomplete responses were not tolerated by the survey system.

Our study is moreover built on respondents' self-reported data. Future research should validate our results by means of objective (as opposed to perception-based) measures of the dependent variables (e.g., supervisor-based performance assessments of employees), wherever possible.

Another limitation is that the collected study data originates from only one organization using one ESS, leaving the question of our results' generalizability to further organizations open (Lee and Baskerville 2003). Although SoftCom's ESS incorporates all the main features that competing ESS platforms offer, it might still be unique in some technological detail and/or in the way it is embedded within the organization under study. Focusing on a single organization prevented us from exploring the role of organizational culture and its potential effects on social connectedness, its antecedents or on the performance impact construct (since we control for culture by studying a single organization). We therefore suggest that researchers should further examine the interplay of cultural characteristics [at the national (e.g., Hofstede 2001), organizational (e.g., Hofstede et al. 1990), and individual (e.g., Alavi et al. 2006) levels] on employees' social connectedness in order to validate our findings in diverse contextual settings.

Moreover, our investigation focused on only one positive outcome of social connectedness, namely individual performance, although prior research has suggested that it has other positive (e.g., an increase in mutual trust: Fehr and List 2004) and negative (e.g., an increase in peer pressure: Bandiera et al. 2005) consequences in an organizational context. Another promising path for future research might therefore be to investigate social connectedness's other potential consequences.

\section{References}

Adler PS, Kwon S-W (2002) Social capital: prospects for a new concept. Acad Manag Rev 27(1):17-40

Alavi M, Leidner DE (2001) Review: knowledge management and knowledge management systems: conceptual foundations and research issues. MIS Q 25(1):107-136

Alavi M, Kayworth TR, Leidner DE (2006) An empirical examination of the influence of organizational culture on knowledge management practices. J Manag Inf Syst 22(3):191-224

Aral S, Dellarocas C, Godes D (2013) Introduction to the special issue - social media and business transformation: a framework for research. Inf Syst Res 24(1):3-13

Ashforth BE, Mael F (1989) Social identity theory and the organization. Acad Manag Rev 14(1):20-39

Bandiera O, Barankay I, Rasul I (2005) Social preferences and the response to incentives: evidence from personnel data. Q J Econ 120(3):917-962

Bandiera O, Barankay I, Rasul I (2008) Social capital in the workplace: evidence on its formation and consequences. Labour Econ 15(4):724-748

Baron RM, Kenny DA (1986) The moderator-mediator variable distinction in social psychological research: conceptual, strategic, and statistical considerations. J Pers Soc Psychol 51(6):1173-1182

Baumeister RF, Leary MR (1995) The need to belong: desire for interpersonal attachments as a fundamental human motivation. Psychol Bull 117(3):497-529

Bock G, Zmud RW, Kim Y, Lee J (2005) Behavioral intentionformation in knowledge sharing: examining the roles of extrinsic motivators, socio-psychological factors, and organizational climate. MIS Q 29(1):87-111

Bowlby J (1982) Attachment and loss: retrospect and prospect. Am J Orthopsychiatry 52(4):664-678

Bradner E (2001) Social affordances of computer-mediated communication technology: understanding adoption. In: Proceedings of the CHI'01 ext abstr hum factors comput syst, Seattle, pp 67-68

Brenner O, Blazini AP, Greenhaus JH (1988) An examination of race and sex differences in managerial work values. J Vocat Behav 32(3):336-344

Burt R (1992) Structural holes: the social structure of competition. Harvard University Press, Cambridge

Chan C, Morgan J (2011) State of enterprise 2.0 collaboration - Q2 2011. Chess Media Group, Vancouver

Chin WW (1998) The partial least squares approach to structural equation modeling. In: Marcoulides GA (ed) Modern methods for business research. Lawrence Erlbaum Associates, Hillsdale, pp 295-336

Chin WW (2004) Frequently asked questions - partial least squares \& PLS-graph: multi-group analysis with PLS. http://disc-nt.cba.uh. edu/chin/plsfaq/contents.htm. Accessed 11 Oct 2013

Chin WW, Marcolin BL, Newsted PR (2003) A partial least squares latent variable modeling approach for measuring interaction effects: results from a monte carlo simulation study and an electronic-mail emotion/adoption study. Inf Syst Res 14(2):189-217 
Cho H (2011) Theoretical intersections among social influences, beliefs, and intentions in the context of $3 \mathrm{G}$ mobile services in singapore: decomposing perceived critical mass and subjective norms. J Commun 61(2):283-306

Chui M, Manyika J, Bughin J, Dobbs R, Roxbough C, Sarrazin H, Sands G, Westergren M (2012) The social economy: unlocking value and productivity through social technologies. McKinsey Global Institute, Washington

Cohen J (1988) Statistical power analysis for the behavioral sciences. Lawrence Erlbaum Associates, Hillsdale

Compeau DR, Higgins CA (1995a) Application of social cognitive theory to training for computer skills. Inf Syst Res 6(2):118-143

Compeau DR, Higgins CA (1995b) Computer self-efficacy: development of a measure and initial test. MIS Q 19(2):189-211

Compeau DR, Meister DB, Higgins CA (2007) From prediction to explanation: reconceptualizing and extending the perceived characteristics of innovating. J Assoc Inf Syst 8(8):211-218

Constant D, Sproull L, Kiesler S (1996) The kindness of strangers: the usefulness of electronic weak ties for technical advice. Organ Sci 7(2):119-135

Cronbach LJ (1951) Coefficient alpha and the internal structure of tests. Psychometrika 16(3):297-334

Cronbach LJ (1971) Test validation. In: Thorndike RL (ed) Educational measurement, 2nd edn. Am Council on Education, Washington, pp 443-507

Cross R, Cummings JL (2004) Tie and network correlations of individual performance in knowledge-intensive work. Acad Manag J 47(6):928-937

De Cremer D, Tyler TR (2005) A matter of intragroup status: the importance of respect for the viability of groups. In: Melissa C, Thomas-Hunt MC (eds) Status and groups (research on managing groups and teams). Emerald Group Publishing Limited, Bingley, pp 1-21

Deci EL, Ryan RM (1987) The Support of autonomy and the control of behavior. J Pers Soc Psychol 53(6):1024-1037

Donath JS (1999) Identity and deception in the virtual community. In: Smith MA, Kollock P (eds) Communities in cyberspace. Routledge, New York, pp 29-59

Dyer J, Nobeoka K (2000) Creating and managing a high performance knowledge-sharing network: the Toyota case. Strateg Manag J 21(3):345-367

Ellison NB, Steinfield C, Lampe C (2007) The benefits of facebook "friends": social capital and college students' use of online social network sites. J Comput-Mediat Commun 12(4):1143-1168

Faraj S, Jarvenpaa SL, Majchrzak A (2011) Knowledge collaboration in online communities. Organ Sci 22(5):1224-1239

Farzan R, DiMicco JM, Brownholtz B (2009) Spreading the honey: a system for maintaining an online community. In: Proceedings of the association for computing machinery (ACM) international conference supporting group work (GROUP), Sanibel Island, pp 31-40

Fehr E, List JA (2004) The hidden costs and returns of incentives trust and trustworthiness among CEOs. J Eur Econ Assoc 2(5):743-771

Fornell C, Larcker DF (1981) Evaluating structural equation models with unobservable variables and measurement error. J Mark Res 18(1):39-50

Frey BS, Jegen R (2001) Motivation crowding theory. J Econ Surv 15(5):589-611

Fulk J, Yuan YC (2013) Location, motivation, and social capitalization via enterprise social networking. J Comput-Mediat Commun 19(1):20-37

Gao G, Hinds P, Zhao C (2013) Closure vs. structural holes: how social network information and culture affect choice of collaborators. In: Proceedings of the 2013 conference on computer supported cooperative work (CSCW'13), San Antonio, pp 5-18

Gefen D, Straub D (2005) A practical guide to factorial validity using PLS-graph: tutorial and annotated example. Commun Assoc Inf Syst 16(1):91-109

Gefen D, Rigdon EE, Straub D (2011) An update and extension to SEM guidelines for administrative and social science research. MIS Q 35(2):iii-xiv

Gerbing DW, Anderson JC (1988) An updated paradigm for scale development incorporating unidimensionality and its assessment. J Mark Res 25(2):186-192

Goffman E (1959) The presentation of self in everyday life. Doubleday, Garden City

Goodhue DL, Thompson RD (1995) Task-technology fit and individual performance. MIS Q 19(2):213-236

Goswami S, Köbler F, Leimeister JM, Krcmar H (2010) Using online social networking to enhance social connectedness and social support for the elderly. In: Proceedings of the 31st international conference on information system (ICIS), St. Louis

Gould S, Werbel JD (1983) Work involvement: a comparison of dual wage earner and single wage earner families. J Appl Psychol 68(2):313-319

Gray PH, Meister DB (2004) Knowledge sourcing effectiveness. Manag Sci 50(6):821-834

Gray PH, Parise S, Iyer B (2011) Innovation impacts of using social bookmarking systems. MIS Q 35(3):629-644

Grieve R, Indian M, Witteveen K, Anne Tolan G, Marrington J (2013) Face-to-face or facebook: can social connectedness be derived online? Comput Hum Behav 29(3):604-609

Gu B, Jarvenpaa S (2003) Online discussion boards for technical support: the effect of token recognition on customer contributions. In: Proceedings of the 24th international conference on information system (ICIS), Seattle

Gu B, Jarvenpaa S (2011) How formal structure of electronic knowledge sharing networks influences participation behavior in a global enterprise. In: Proceedings of the 32nd international conference on information system (ICIS), Shanghai

Hair JF, Sarstedt M, Pieper TM, Ringle CM (2012a) The use of partial least squares structural equation modeling in strategic management research: a review of past practices and recommendations for future applications. Long Range Plan 45(5-6):320-340

Hair JF, Sarstedt M, Ringle CM, Mena JA (2012b) An assessment of the use of partial least squares structural equation modeling in marketing research. J Acad Mark Sci 40(3):414-433

Hamari J, Koivisto J, Sarsa H (2014) Does gamification work? A literature review of empirical studies on gamification. In: Proceedings of the 47th Hawaii international conference on system science (HICSS-47), Big Island, pp 3025-3034

Hansen MT (1999) The search-transfer problem: the role of weak ties in sharing knowledge across organization subunits. Adm Sci Q 44(1):82-111

Healey M (2011) Rebooting the antisocial network. InformationWeek Reports. InformationWeek, New York

Healey M (2012) Dislike - why employees aren't taking to enterprise social networks, and what it can do to help. InformationWeek Reports. InformationWeek, New York

Helm S, Eggert A, Garnefeld I (2010) Modeling the impact of corporate reputation on customer satisfaction and loyalty using partial least squares. In: Esposito Vinzi V, Chin WW, Henseler J, Wang $\mathrm{H}$ (eds) Handbook of partial least squares. Springer, Heidelberg, pp 515-534

Hester A (2011) A comparative analysis of the usage and infusion of wiki and non-wiki-based knowledge management systems. Inf Technol Manag 12(4):335-355 
Hofstede GH (2001) Culture's consequences: comparing values, behaviors, institutions and organizations across nations. SAGE Publications Inc, Thousand Oaks

Hofstede G, Neuijen B, Ohayv DD, Sanders G (1990) Measuring organizational cultures: a qualitative and quantitative study across twenty cases. Adm Sci Q 35(2):286-316

Hsu C-L, Lin JC-C (2008) Acceptance of blog usage: the roles of technology acceptance, social influence and knowledge sharing motivation. Inf Manag 45(1):65-74

Hsu C-L, Lu H-P (2004) Why do people play on-line games? An extended tam with social influences and flow experience. Inf Manag 41(6):853-868

Huotari K, Hamari J (2012) Defining gamification: a service marketing perspective. In: Proceedings of the the 16th international academic mindtrek conference, Tampere, pp 17-22

IBM Corporation (2012) IBM SPSS statistics 21.0

Iivari J (2005) An empirical test of the delone-mclean model of information system success. Data Base Adv Inf Syst 36(2):8-28

Iivari J (2014) Perceived sociability of use and individual use of social networking sites - a field study of facebook use in the arctic. Open J Inf Syst 1(1):23-53

Ijsselsteijn W, van Baren J, van Lanen F (2003) Staying in touch: social presence and connectedness through synchronous and asynchronous communication media. In: Proceedings of the 10th international conference on human-computer interactions, Crete, pp 924-928

Ijsselsteijn W, van Baren J, Markopoulos P, Romero N, De Ruyter B (2009) Measuring affective benefits and costs of mediated awareness: development and validation of the abc-questionnaire. In: Markopoulos P, De Ruyter B, Mackay W (eds) Awareness systems. Springer, Heidelberg, pp 473-488

Jansen JJP, Van Den Bosch FAJ, Volberda HW (2006) Exploratory innovation, exploitative innovation, and performance: effects of organizational antecedents and environmental moderators. Manag Sci 52(11):1661-1674

Jasperson JS, Carter PE, Zmud RW (2005) A comprehensive conceptualization of post-adoptive behaviours associated with information technology enabled work systems. MIS Q 29(3):525-557

Jaworski BJ, Kohli AK (1993) Market orientation: antecedents and consequences. J Mark 57(3):53-70

Jeppesen LB, Frederiksen L (2006) Why do users contribute to firmhosted user communities? The case of computer-controlled music instruments. Organ Sci 17(1):45-63

Jung J, Schneider C, Valacich J (2010) Enhancing the motivational affordance of information systems: the effects of real-time performance feedback and goal setting in group collaboration environments. Manag Sci 56(4):724-742

Kane GC, Fichman RG (2009) The shoemaker's children: using wikis for information systems teaching, research, and publication. MIS Q 33(1):1-17

Kane GC, Fichman RG, Gallaugher J, Glaser J (2009) Community relations 2.0. Harv Bus Rev 87(11):45-50

Kane GC, Alavi M, Labianca GJ, Borgatti SP (2014a) What's different about social media networks: a framework and research agenda. MIS Q 38(1):275-304

Kane GC, Palmer D, Phillips AN, Kiron D (2014b) Finding the value in social business. MIT Sloan Manag Rev 55(3):81-88

Kankanhalli A, Tan BCY, Wei K-K (2005) Contributing knowledge to electronic knowledge repositories: an empirical investigation. MIS Q 29(1):113-143

Karahanna E, Straub DW, Chervany NL (1999) Information technology adoption across time: a cross-sectional comparison of pre-adoption and post-adoption beliefs. MIS Q 23(2):182-213

Katz ML, Shapiro C (1986) Technology adoption in the presence of network externalities. J Polit Econ 94(4):822-841
Kim H, Kim GJ, Park HW, Rice RE (2007) Configurations of relationships in different media: $\mathrm{ftf}$, email, instant messenger, mobile phone, and sms. J Comput-Mediat Commun 12(4):1183-1207

Kiron D, Palmer D, Nguyen Phillips A, Berkman R (2013) Social business: shifting out of first gear. MIT Sloan Manag Rev Res Rep, Cambridge

Köbler F, Riedl C, Vetter C, Leimeister JM, Krcmar H (2010) Social connectedness on facebook - an explorative study on status message usage. In: Proceedings of the 16th American conference on information system (AMCIS), Lima

Koroleva K, Krasnova H, Veltri N, Günther O (2011) It's all about networking! empirical investigation of social capital formation on social network sites. In: Proceedings of the 32nd international conference on information system (ICIS), Shanghai

Krasnova H, Spiekermann S, Koroleva K, Hildebrand T (2010) Online social networks: why we disclose. J Inf Technol 25(2):109-125

Krasnova H, Veltri NF, Günther O (2012) Self-disclosure and privacy calculus on social networking sites: the role of culture. Bus Inf Syst Eng 4(3): 125-127

Kügler M, Smolnik S, Raeth P (2012) Why don't you use it? Assessing the determinants of enterprise social software usage: a conceptual model integrating innovation diffusion and social capital theories. In: Proceedings of the 33rd international conference on information system (ICIS), Orlando

Lam C (2013) The efficacy of text messaging to improve social connectedness and team attitude in student technical communication projects: an experimental study. J Bus Tech Commun 27(2): 180-208

Lampe CA, Ellison N, Steinfield C (2007) A familiar face (book): profile elements as signals in an online social network. In: Proceedings of the special interest group on computer-human interaction (SIGCHI) conference on human factors computer system. San Jose, pp 435-444

Ledbetter AM, Mazer JP, DeGroot JM, Meyer KR, Mao Y, Swafford B (2011) Attitudes toward online social connection and selfdisclosure as predictors of facebook communication and relational closeness. Commun Res 38(1):27-53

Lee AS, Baskerville RL (2003) Generalizing generalizability in information systems research. Inf Syst Res 14(3):221-243

Lee RM, Robbins SB (1995) Measuring belongingness: the social connectedness and the social assurance scales. J Couns Psychol 42(2):232-241

Lee RM, Draper M, Lee S (2001) Social connectedness, dysfunctional interpersonal behaviors, and psychological distress: testing a mediator model. J Couns Psychol 48(3):310-318

Leonardi PM, Huysman M, Steinfield C (2013) Enterprise social media: definition, history, and prospects for the study of social technologies in organizations. J Comput-Mediat Commun 19(1):1-19

Li D, Chau PYK, Lou H (2005) Understanding individual adoption of instant messaging: an empirical investigation. J Assoc Inf Syst 6(4):102-129

Lin C-P, Bhattacherjee A (2008) Elucidating individual intention to use interactive information technologies: the role of network externalities. Int J Electron Commer 13(1):85-108

Lin CP, Bhattacherjee A (2010) Extending technology usage models to interactive hedonic technologies: a theoretical model and empirical test. Inf Syst J 20(2):163-181

Lin K-Y, Lu H-P (2011) Why people use social networking sites: an empirical study integrating network externalities and motivation theory. Comput Hum Behav 27(3):1152-1161

Lou H, Luo W, Strong D (2000) Perceived critical mass effect on groupware acceptance. Europ J Inf Syst 9(2):91-103 
Lowry PB, Gaskin J (2014) Partial least squares (PLS) structural equation modeling (SEM) for building and testing behavioral causal theory: when to choose it and how to use it. IEEE Trans Prof Commun 57(2):123-146

Lu Y, Deng Z, Wang B (2010) Exploring factors affecting chinese consumers' usage of short message service for personal communication. Inf Syst J 20(2):183-208

MacKenzie SB, Podsakoff PM, Podsakoff NP (2011) Construct measurement and validation procedures in mis and behavioral research: integrating new and existing techniques. MIS Q 35(2):293-334

Majchrzak A, Cherbakov L, Ives B (2009) Harnessing the power of the crowds with corporate social networking tools: how ibm does it. MIS Q Exec 8(2):103-108

Majchrzak A, Faraj S, Kane GC, Azad B (2013) The contradictory influence of social media affordances on online knowledge affordances. J Comput-Mediat Commun 19(1):38-55

Markus ML (1987) Toward a "critical mass" theory of interactive media: universal access, interdependence and diffusion. Commun Res 14(5):491-511

Markus ML, Connolly T (1990) Why CSCW applications fail: problems in the adoption of interdependent work tools. In: Proceedings of the association for computing machinery (ACM) conference on computer-supported cooperative work (CSCW), Los Angeles, pp 371-380

Maslow AH (1968) Toward a psychology of being. Van Nostrand Reinhold Publishing, New York

McAfee A (2009) Shattering the myths about enterprise 2.0. Harv Bus Rev 87(11):1-6

Meehl PE (1990) Why Summaries of research on psychological theories are often uninterpretable. Psychol Rep 66(1):195-244

Mom TJM, Van Den Bosch FAJ, Volberda HW (2009) Understanding variation in managers' ambidexterity: investigating direct and interaction effects of formal structural and personal coordination mechanisms. Organ Sci 20(4):812-828

Moore GC, Benbasat I (1991) Development of an instrument to measure the perceptions of adopting an information technology innovation. Inf Syst Res 2(3):192-222

Nunnally JC, Bernstein IH (1994) Psychometric teory, 3rd edn. McGraw-Hill Inc, New York

Pawlowski JM, Bick M, Peinl R, Thalmann S, Maier R, Hetmank L, Kruse P, Martensen M, Pirkkalainen H (2014) Social knowledge environments. Bus Inf Syst Eng 6(2):81-88

Phang CW, Kankanhalli A, Sabherwal R (2009) Usability and sociability in online communities: a comparative study of knowledge seeking and contribution. J Assoc Inf Syst 10(10):721-747

Plouffe CR, Hulland JS, Vandenbosch M (2001) Richness versus parsimony in modeling technology adoption decisions - understanding merchant adoption of a smart card-based payment system. Inf Syst Res 12(2):208-222

Rettie R (2003a) A comparison of four new communication technologies. In: Jacko J, Stephanidis C (eds) Human-computer interaction: theory and practice. Lawrence Erlbaum Associates, Mahwah, pp 686-690

Rettie R (2003) Connectedness, awareness and social presence. In: Proceedings of the annual international workshop on presence (PRESENCE), Aalborg

Richter A, Riemer K (2013) Malleable end-user software. Bus Inf Syst Eng 5(3):195-197

Richter D, Riemer K, vom Brocke J (2011) Internet social networking. Bus Inf Syst Eng 3(2):89-103

Riedl C, Köbler F, Goswami S, Krcmar H (2013) Tweeting to feel connected: a model for social connectedness in online social networks. Int J Hum-Computr Interact 29(10):670-687
Riemer K, Stieglitz S, Meske C (2015) From top to bottom: investigating the changing role of hierarchy and influence in enterprise social networks. Bus Inf Syst Eng 57(3)

Ringle CM, Wende S, Will A (2005) SmartPLS 2.0 M3. http://www. smartpls.de. Accessed 15 Nov 2012

Riordan CM, Vandenberg RJ, Richardson HA (2005) Employee involvement climate and organizational effectiveness. Hum Resour Manag 44(4):471-488

Roca JC, Gagné M (2008) Understanding e-learning continuance intention in the workplace: a self-determination theory perspective. Comput Hum Behav 24(4):1585-1604

Rogers EM (1983) Diffusion of innovations, 3rd edn. Free Press, New York

Ross C, Orr ES, Sisic M, Arseneault JM, Simmering MG, Orr RR (2009) Personality and motivations associated with facebook use. Comput Hum Behav 25(2):578-586

Ryan RM, Deci EL (2000) Self-determination theory and the facilitation of intrinsic motivation, social development, and well-being. Am Psychol 55(1):68-78

Satterthwaite FE (1946) An approximate distribution of estimates of variance components. Biom Bull 2(6):110-114

Scheepers H, Stockdale R, Scheepers R, Nurdin N (2014) The dependent variable in social media use. J Comput Inf Syst $54(2): 25-34$

Schöndienst V, Günther O, Krasnova H, Riehle D (2011) Microblogging adoption in the enterprise. In: Proceedings of the 10th international conference on Wirtschaftsinformatik (WI), Zurich

Shin D-H (2010) Analysis of online social networks: a cross-national study. Online Inf Rev 34(3):473-495

Sledgianowski D, Kulviwat S (2009) Using social network sites: the effects of playfulness, critical mass and trust in a hedonic context. J Comput Inf Syst 49(4):74-83

Smith ER, Mackie DM (2007) Social psychology, 3rd edn. Hove, New York

Sobel ME (1982) Asymptotic confidence intervals for indirect effects in structural equation models. In: Leinhart S (ed) Sociological methodology. Jossey-Bass, San Francisco, pp 290-312

Stone EF (1978) Research methods in organizational behavior. Goodyear, Santa Monica

Straub DW (1989) Validating instruments in MIS research. MIS Q 13(2):147-169

Subrahmanyam K, Reich SM, Waechter N, Espinoza G (2008) Online and offline social networks: use of social networking sites by emerging adults. J Appl Dev Psychol 29(6):420-433

Suh A, Shin K-S, Ahuja M, Kim MS (2011) The influence of virtuality on social networks within and across work groups: a multilevel approach. J Manag Inf Syst 28(1):351-386

Sundaram S, Schwarz A, Jones E, Chin WW (2007) Technology use on the front line: how information technology enhances individual performance. J Acad Mark Sci 35(1):101-112

Sykes TA, Venkatesh V, Johnson JL (2014) Enterprise system implementation and employee job performance: understanding the role of advice networks. MIS Q 38(1):51-72

Teigland R, Wasko MM (2003) Integrating knowledge through information trading: examining the relationship between boundary spanning communication and individual performance. Decis Sci 34(2):261-286

Tesluk PE, Jacobs RR (1998) Toward an integrated model of work experience. Pers Psychol 51(2):321-355

Thom J, Millen D, DiMicco J (2012) Removing gamification from an enterprise SNS. In: Proceedings of the association on computing machinery (ACM) conference on computer-supported cooperative work (CSCW), Bellevue, pp 1067-1070

Thompson R, Higgins CA, Howell JM (1991) Personal computing: toward a conceptual model of utilization. MIS Q 15(1):125-143 
Tong ST, Van Der Heide B, Langwell L, Walther JB (2008) Too much of a good thing? The relationship between number of friends and interpersonal impressions on facebook. J ComputMediat Commun 13(3):531-549

Townsend KC, McWhirter BT (2005) Connectedness: a review of the literature with implications for counseling, assessment, and research. J Couns Dev 83(2):191-201

Trier M, Richter A (2014) The deep structure of organizational online networking - an actor-oriented case study. Inf Syst J. (forthcoming)

Urbach N, Smolnik S, Riempp G (2010) An empirical investigation of employee portal success. J Strateg Inf Syst 19(3):184-206

Utz S (2010) Show me your friends and I will tell you what type of person you are: how one's profile, number of friends, and type of friends influence impression formation on social network sites. J Comput-Mediat Commun 15(2):314-335

Valkenburg PM, Peter J (2009) Social consequences of the internet for adolescents: a decade of research. Curr Dir Psychol Sci $18(1): 1-5$

Vallerand RJ (1997) Toward a hierarchical model of intrinsic and extrinsic motivation. In: Zanna MP (ed) Advances in experimental social psychology. Academic Press, San Diego, pp 271-360

Van Slyke C, Ilie V, Lou H, Stafford T (2007) Perceived critical mass and the adoption of a communication technology. Eur J Inf Syst 16(3):270-283

Venkatesh V (1999) Creation of favorable user perceptions: exploring the role of intrinsic motivation. MIS Q 23(2):239-260

Venkatesh V, Morris MG (2000) Why don't men ever stop to ask for directions? Gender, social influence, and their role in technology acceptance and usage behavior. MIS Q 24(1):115-139

Venkatesh V, Morris MG, Davis GB, Davis FD (2003) User acceptance of information technology: toward a unified view. MIS Q 27(3):425-478

von Krogh G (2012) How does social software change knowledge management? Toward a strategic research agenda. J Strateg Inf Syst 21(2):154-164

Wang C-C, Hsu Y, Fang W (2004) Acceptance of technology with network externalities: an empirical study of internet instant messaging services. J Inf Technol Theory Appl 6(4):15-28
Wasko MM, Faraj S (2005) Why should i share? Examining social capital and knowledge contribution in electronic networks of practice. MIS Q 29(1):35-57

Wasko MM, Faraj S, Teigland R (2004) Collective action and knowledge contribution in electronic networks of practice. J Assoc Inf Syst 5(11-12):493-513

Wattal S, Racherla P, Mandviwalla M (2010) Network externalities and technology use: a quantitative analysis of intraorganizational blogs. J Manag Inf Syst 27(1):145-174

Wilden R, Gudergan SP (2014) The impact of dynamic capabilities on operational marketing and technological capabilities: investigating the role of environmental turbulence. J Acad Mark Sci. Forthcoming

Wu L (2013) Social network effects on productivity and job security: evidence from the adoption of a social networking tool. Inf Syst Res 24(1):30-51

Wu A, DiMicco JM, Millen DR (2010) Detecting professional versus personal closeness using an enterprise social network site. In: Proceedings of the special interest group on computer-human interaction (SIGCHI) conference on human factors computer system, Atlanta

Xu Y, Yang Y, Cheng Z, Lim J (2014) Retaining and attracting users in social networking services: an empirical investigation of cyber migration. J Strateg Inf Systems. Forthcoming

Yoon E, Lee RM (2010) Importance of social connectedness as a moderator in Korean immigrants' subjective well-being. Asian Am J Psychol 1(2):93-105

Yoon E, Hacker J, Hewitt A, Abrams M, Cleary S (2012) Social connectedness, discrimination, and social status as mediators of acculturation/enculturation and well-being. J Couns Psychol 59(1):86-96

Zhang X, Venkatesh V (2013) Explaining employee job performance: the role of online and offline workplace communication networks. MIS Q 37(3):695-722

Zhang X, Wang C (2012) Network positions and contributions to online public goods: the case of Chinese wikipedia. J Manag Inf Syst 29(2):11-40 